\title{
Slow recovery of the right and left ventricular deformation after conversion from atrial fibrillation
}

\author{
Roman Leischik, Henning Littwitz \\ Dept. Prevention and Sports Medicine, University Witten-Herdecke, Chair Cardiology, Prof. M. Seyfarth, Hagen, Germany
}

Email address:

info@dr-leischik.de (R. Leischik)

\section{To cite this article:}

Roman Leischik, Henning Littwitz. Slow Recovery of the Right and Left Ventricular Deformation after Conversion from Atrial Fibrillation. American Journal of Sports Science. Vol. 2, No. 2, 2014, pp. 13-16. doi: 10.11648/j.ajss.20140202.11

\begin{abstract}
Atrial fibrillation (AF) is a possible complication of sport in middle-aged athletes. When sinus rhythm has been restored, at what time is deformation restored too? This question has never been answered. We studied an one 47-year old cyclist and runner with acute lone atrial fibrillation. A day before, he trained hard intervals and felt at the next day an irregular rhythm, training was not possible. He told this would occure 2 times a year, but after the light training the irregular puls will disappear. At the chest-pain unit we performed echocardiography inclusive strain measurements of the right and left ventricle during atrial fibrillation and immediately after the recovery of the sinus rhythm. He recovered to sinus rhythm during the exercise test. Global strain was at the moment of atrial fibrillation $-11.8 \%$, direct after the recovery of the sinus rhythm $-17,2 \%$, and $-20.5 \%$ at the next day, even though the normalized diastolic function directly after conversion from AF. It seems to be that the heterogenity of the deformation need time to recovery after the conversion to the sinus rhythm, even though the diastolic function seems to be normalized. The further endurance training should be continued only after normalization of deformation values.
\end{abstract}

Keywords: Atrial Fibrillation, Endurance Sport, Deformation, Strain-Echocardiography, Cardiac Fatique

\section{Introduction}

Atrial fibriallation (AF) related to sport is known phenomenon since the 60-ties [1]. The recurrent atrial fibrillation in athletes has a variety of reasons: individual disposition, underlying atrial or conductional disease. Other reasons are speculative too: atrial ectopic beats, inflammatory changes, changes in electrolytes, atrial enlargement with dilatation, increased vagal tone [2]. There are different reports about the risk of AF in endurance athletes. The most of them refer an increased risk of AF in endurance athletes in comparison to general population [2] , in contrast only Pelicca at al. [3] reported about low incidence of AF among competitive athletes (0.2\%) similar to that general populations of comparable age or sex.

In the ongoing search for possibilities to overcome the subjectivity of echocardiography as a diagnostic tool for the assessment of LV function [4], novel quantitative technique for deformation analysis has been introduced. Strain is defined as the speed at which deformation occurs, shortening is often expressed as negative strain and as percentage [5]. Besides the advantages that strain imaging offer, there is still a number of challenges that limit their clinical utility such as challenging image acquisition and a lack of consensus regarding optimal parameters and methods. Global Strain measurement seems to be easy and practicable in clinical setting [6] to assess the left [6] and right ventricular function [7].

\section{Case Report}

One 47-year old cyclist and runner $(172 \mathrm{~cm} / 72 \mathrm{~kg}),(1 \mathrm{x}$ Trans-Alp, Half-Marathon time 1.30h) has since 8 years $2 \mathrm{x}$ year AF-events. He train 6 days a week ( $4 x$ times bike for 3-5 hours) and runs $50 \mathrm{~km}$ weekly since 6 years. He lost 5 years before $50 \mathrm{~kg}$ weight, because he was extremely obese. Endurance sport was for him a part of the lifestyle change. Underlying illness is not known. Arterial hypertension is not known. He developed AF suddenly, one day after hard training with intervalls up to 150 to 280/Watts over 2 hours. Training in this day was not possible, he took $100 \mathrm{mg}$ flecainid, but nothing happened, so he came to the cardiologic chest pain unit. He reported, in cases of AF, he would obtain sinus rhythm after light bike-training. 


\section{Methods and Results}

The echocardiographic exam [8] was performed with the commercially available ultrasound device VIVID 9 by General Electrics (GE) Medical Systems GmbH, Germany. The ultrasound probe that was used is a "Matrix Array"; Sector $3.5-4.3 \mathrm{MHz}$. The recorded data were transferred by a local network and saved on a storage device. For the exercise test an Ergoline stressecho-chair was used. Strain-Echocardiography was performed in the AFI-Mode [6]. For the right ventricle analysis we used only the 4 apical-view and the P-Lax option in the AFI-program.

In 12-canal ECG a typical atrial fibrillation could be noted. 2-D Echocardiography showed normal left atrial dimensions $(3,6 \mathrm{~cm} / 38 \mathrm{ml}$ volume $)$ and normal left ventricular size $(4,7 \mathrm{~cm} / 100 \mathrm{ml}$ enddiastolic volume). Myocardial thickness was with $11 \mathrm{~mm}$ normal (septum and posterior wall). Right ventricular volume was $38 \mathrm{ml}$ without enlargement. We decided to perform stress-echocardiography to assess a possible cardiac dysfunction during exercise and to obtain a conversion to the sinus rhythm regarding the successfully recovery in the patients history. We used the Bruce-protocol with 50 Watts and increased each 2 minutes 25 watts. At 125 Watts level and 140heart rate, sinus rhythm occurred. There were no signs of ischemia during the exercise in regarding the stress-echocardiography, during AF, ECG was not interpretable in cause of false-positive ST-depression due to the AF. Strain echocardiography was performed at rest 5 minutes after the peak exercise. Strain values of the different time points are visualized for all left ventricular views (Table 1).

It is shown in the Figure 2, that the deformation of the right ventricle after 24 hours is not homogenous in comparison to the left ventricle. It could be caused by the "exercised induced cardiac fatique" of the right ventricle. This issue is already under discussion $[9,10]$. LaGerche et al. [9] described right ventricular "overload" after vigorous exercise.

Table 1.Strain Values

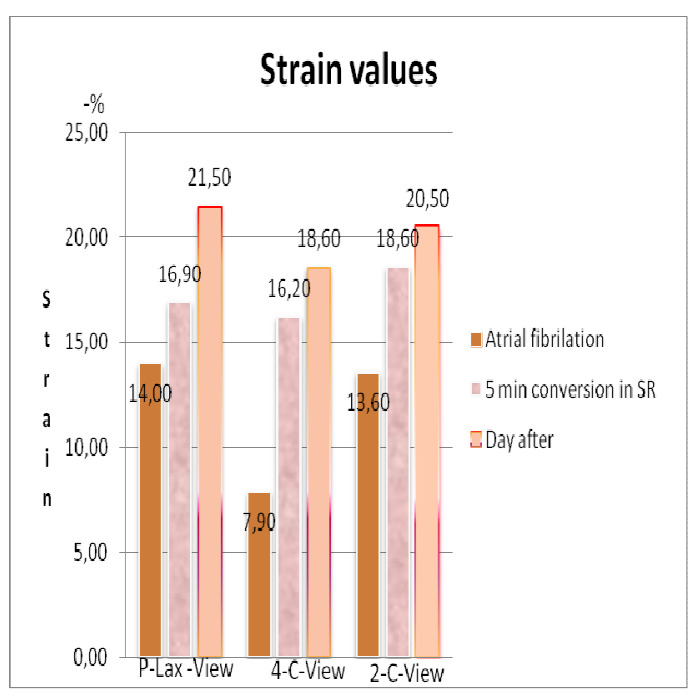

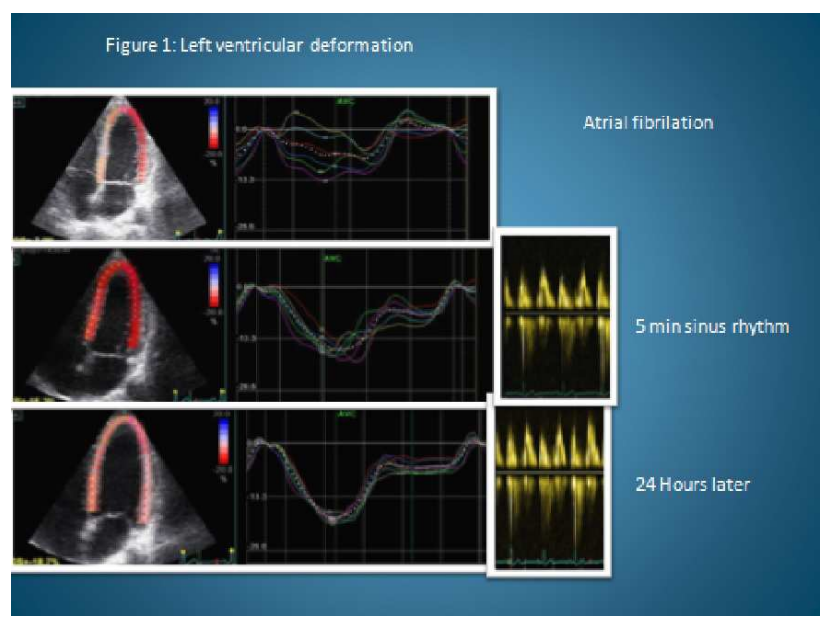

Figure 1. Left ventricular deformation during atrial fibrillation, 5 Min after conversion to sinus rhythm and 24 hours later

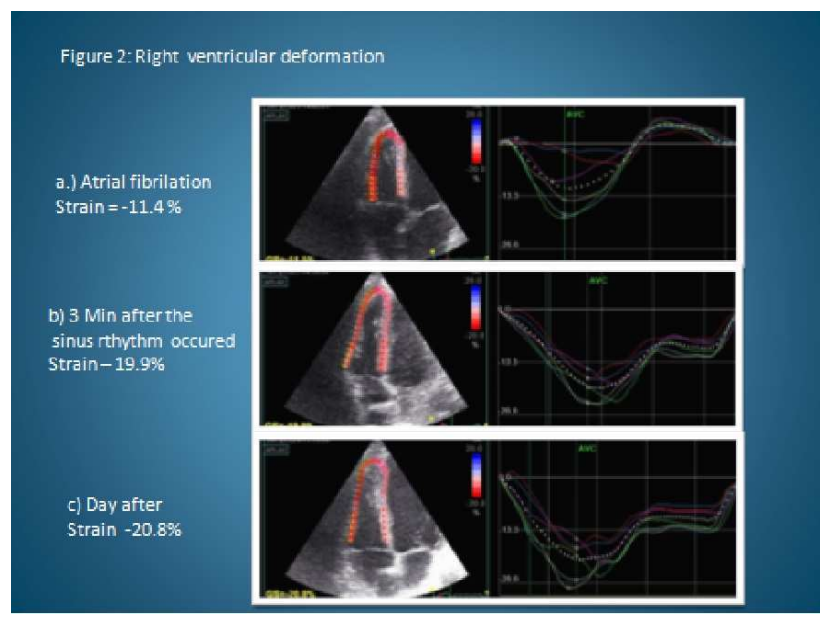

Figure 2. Right ventricular deformation during atrial fibrillation, 3Min after conversion to sinus rhythm and 24 hours later

\section{Discussion}

Atrial fibrillation in middle aged athletes is one common phenomenon. The athletes have higher risk for AF than controls (OR 5.29 (CI 3.57-7.85). For therapy we have the option of the intermittent drug therapy or the better option of circumferential pulmonary vein ablation [11]. Long term drug therapy introduces a lot of problems with decreased performance of the athletes or pro-arrhythmogenic effects caused by changes of electrolytes. In cases of occurred AF in endurance athletes we have to try to find the possible reason of the arryththmia. The problem is there are e a lot of possibilities [2, 12]. Gallagher at al. [13] discussed a broad field of underlying diseases from myocarditis to myocardial degeneration. The last problem is under scientific discussion. The degeneration and fibrosis of the atrial tissue is one possible mechanisms [14].

It is not known how much physical activity is good for health $[15,16]$. One of the recommendations is to use $490 / \mathrm{kcal} /$ day regarding to Late Paeolithic times (50000-10000 BP) [17]. The further proposal is to be active up to $41 /$ Mets-hrs/day [18]. For all "joggers" or 
ambitious middle aged triathletes it is not enough. They have to train and suffer from arrhythmias, but they live longer [19-21]. The study by Marijon et al. [22] reports positive effects professional endurance sport. Professional cyclists presented a $41 \%$ percent lower all-cause mortality than the general population. Also the current meta-analysis by Teramoto and Bungum [23] reports a lower mortality (especially cardiovascular) and a longer life span of elite athletes. Of course, the results have to be interpreted with caution. Lifestyle and genetic predisposition may be more advantageous than the variables in the general population. The investigation of 2612 male elite athletes of Sarna et al. [24] also showed an increase in life-expectancy of endurance athletes compared with the control group (75.6 vs. 69.0 years).

There is no doubt, that athletes have a higher incidence of atrial fibrillation an bradyarrhythmia in old age $[2,19]$. The relevance of possible fibrosis of the left atrium remains open [14]. In the case of 52.755 cross-country skyers of the Vasa-race [19] atrial fibrillation and bradyarrhythmia occurs more frequently (14.3/10000/patients/years and 1.9-2.8/10000/ patients/years). However frequent occurrence of supraventricular/ventricular tachycardia and cardiac arrest compared with the general population was not seen.

The general discussion of arrhythmias and sport remains controversial, because the causes and effects are still not clear at present (underlying disease, predisposition, training situation, circumstances). Sport itself is not arrhythmogenic. It needs perhaps a "triggerpoint": an inflammation or genetic disposition [13].

The recent general reviews on the potential side effects of ambitious endurance sport have partly different views. Scharhag et al. [25] thesis is that ambitious endurance sport will not lead to a myocardial damage or negative effects. O'Keefe et al. [26] agree with the statement that ambitious endurance athletes have lower mortality ratios, however, they also suggest the hypothesis that excessive endurance training may lead to negative cardiovascular remodeling. To verify this hypothesis endurance athletes should be identified. The latest publication of the Nixdorf-Recoll study revealed that for older athletes $>50$ years not the increase in troponin during marathon, but the individual risk of cardiovascular disease is of prognostic significance [27]. These studies indicate that endurance sport per se does not present a risk, but that "individual burden of disease" determines the risk for mortality.

\section{Critical View}

We introduced strain measurements for the situation of AF. We are using only one cardiac cycle (from R-wave to $\mathrm{R}$-wave), so we can obtain one strain-value for a practical assess of the left or right ventricular deformation. In our opinion this assess of deformation can be used, even though AF occurred. Otherwise we have only the conventional assessment [8]. We observed that in cases of advanced heart failure with AF, the strain values decreased further until $-8 \%$. We considered, it might be possible to use this method and we have to develop further studies in similar issues.

\section{Summary}

Atrial fibrillation (AF) in the endurance athletes $>45$ years endurance sport is common phenomenon [2]. The prevention of frequency of arrhythmias or atrial fibrillation in athletes is unknown. It is possibly, that aerobic training [28] and consequent treatment of arterial hypertension [29] have the impact to avoid the frequency of occurrence of AF. The treatment with ACE inhibitors or AT1-receptor antagonists is seems to be one option [30, 31]. Further studies on this issue are necessary.

\section{References}

[1] Zehender, M., T. Meinertz, J. Keul and H. Just (1990) ECG variants and cardiac arrhythmias in athletes: clinical relevance and prognostic importance. Am Heart J. 119, 1378-1391.

[2] Calvo, N., J. Brugada, M. Sitges and L. Mont (2012) Atrial fibrillation and atrial flutter in athletes. Br J Sports Med. 46 Suppl 1, i37-43.

[3] Pelliccia, A., B.J. Maron, F.M. Di Paolo, A. Biffi, F.M. Quattrini, C. Pisicchio, A. Roselli, S. Caselli and F. Culasso (2005) Prevalence and clinical significance of left atrial remodeling in competitive athletes. J Am Coll Cardiol. 46, 690-696.

[4] Voigt, J.-U., B. Exner, K. Schmiedehausen, C. Huchzermeyer, U. Reulbach, U. Nixdorff, G. Platsch, T. Kuwert, W.G. Daniel and F.A. Flachskampf (2003) Strain-rate imaging during dobutamine stress echocardiography provides objective evidence of inducible ischemia. Circulation. 107, 2120-2126.

[5] Heimdal, A., A. Støylen, H. Torp and T. Skjærpe (1998) Real-time strain rate imaging of the left ventricle by ultrasound. Journal of the American Society of Echocardiography. 11, 1013-1019.

[6] Feigenbaum, H., R. Mastouri and S. Sawada (2012) A practical approach to using strain echocardiography to evaluate the left ventricle. Circ J. 76, 1550-1555.

[7] Simsek, Z., M.H. Tas, E. Gunay and H. Degirmenci (2013) Speckle-tracking echocardiographic imaging of the right ventricular systolic and diastolic parameters in chronic exercise. Int J Cardiovasc Imaging. 29, 1265-1271.

[8] Lang, R.M., M. Bierig, R.B. Devereux, F.A. Flachskampf, E. Foster, P.A. Pellikka, M.H. Picard, M.J. Roman, J. Seward and J. Shanewise (2006) Recommendations for chamber quantification. European Journal of Echocardiography. 7, 79-108.

[9] La Gerche, A., A.T. Burns, D.J. Mooney, W.J. Inder, A.J. Taylor, J. Bogaert, A.I. MacIsaac, H. Heidbüchel and D.L. Prior (2012) Exercise-induced right ventricular dysfunction and structural remodelling in endurance athletes. European heart journal. 33, 998-1006. 
[10] Oxborough, D., K. Birch, R. Shave and K. George (2010) "Exercise-induced cardiac fatigue"--a review of the echocardiographic literature. Echocardiography. 27, 1130-1140.

[11] Calvo, N., L. Mont, D. Tamborero, A. Berruezo, G. Viola, E. Guasch, M. Nadal, D. Andreu, B. Vidal and M. Sitges (2010) Efficacy of circumferential pulmonary vein ablation of atrial fibrillation in endurance athletes. Europace. 12, 30-36.

[12] Lubitz, S.A., E.J. Benjamin, J.N. Ruskin, V. Fuster and P.T. Ellinor (2010) Challenges in the classification of atrial fibrillation. Nat Rev Cardiol. 7, 451-460.

[13] Gallagher, M.M. and J. Camm (1998) Classification of atrial fibrillation. Am J Cardiol. 82, 18n-28n.

[14] Burstein, B. and S. Nattel (2008) Atrial Fibrosis: Mechanisms and Clinical Relevance in Atrial Fibrillation. Journal of the American College of Cardiology. 51, 802-809.

[15] Blair, S.N., H.W. Kohl, N.F. Gordon and R.S. Paffenbarger, Jr. (1992) How much physical activity is good for health? Annu Rev Public Health. 13, 99-126.

[16] Lee, I.M. and P.J. Skerrett (2001) Physical activity and all-cause mortality: what is the dose-response relation? Med Sci Sports Exerc. 33, S459-471; discussion S493-454.

[17] Eaton, S.B., L. Cordain and S. Lindeberg (2002) Evolutionary Health Promotion: A Consideration of Common Counterarguments. Preventive Medicine. 34, 119-123.

[18] Bellavia, A., M. Bottai, A. Wolk and N. Orsini (2013) Physical activity and mortality in a prospective cohort of middle-aged and elderly men - a time perspective. Int $\mathrm{J}$ Behav Nutr Phys Act. 10, 94.

[19] Andersen, K., B. Farahmand, A. Ahlbom, C. Held, S. Ljunghall, K. Michaelsson and J. Sundstrom (2013) Risk of arrhythmias in 52755 long-distance cross-country skiers: a cohort study. Eur Heart J.

[20] Farahmand, B.Y., A. Ahlbom, O. Ekblom, B. Ekblom, U. Hallmarker, D. Aronson and G.P. Brobert (2003) Mortality amongst participants in Vasaloppet: a classical long-distance ski race in Sweden. J Intern Med. 253, 276-283.

[21] Gajewski, A.K. and A. Poznanska (2008) Mortality of top athletes, actors and clergy in Poland: 1924-2000 follow-up study of the long term effect of physical activity. Eur $\mathrm{J}$ Epidemiol. 23, 335-340.

[22] Marijon, E., M. Tafflet, J. Antero-Jacquemin, N. El Helou, G. Berthelot, D.S. Celermajer, W. Bougouin, N. Combes, O. Hermine and J.-P. Empana (2013) Mortality of French participants in the Tour de France (1947-2012). European heart journal. 34, 3145-3150.

[23] Teramoto, M. and T.J. Bungum (2010) Mortality and longevity of elite athletes. J Sci Med Sport. 13, 410-416.

[24] Sarna, S., T. Sahi, M. Koskenvuo and J. Kaprio (1993) Increased life expectancy of world class male athletes. Med Sci Sports Exerc. 25, 237-244.

[25] Scharhag, J., H. Lollgen and W. Kindermann (2013) Competitive sports and the heart: benefit or risk? Dtsch Arztebl Int. 110, 14-23; quiz 24; e11-12.

[26] O'Keefe, J.H., R.P. Harshal, C.J. Lavie, A. Magalski, R.A. Vogel and P.A. McCiiough (2012) Potential Adverse Cardiovascular Effects From Excessive Endurance Exercise. Mayo Clin Proc. 87, 587-595.

[27] Mohlenkamp, S., K. Leineweber, N. Lehmann, S. Braun, U. Roggenbuck, M. Perrey, M. Broecker-Preuss, T. Budde, M. Halle, K. Mann, K.H. Jockel, R. Erbel, and G. Heusch (2014) Coronary atherosclerosis burden, but not transient troponin elevation, predicts long-term outcome in recreational marathon runners. Basic Res Cardiol. 109, 391.

[28] Whelton, S.P., A. Chin, X. Xin and J. He (2002) Effect of aerobic exercise on blood pressure: a meta-analysis of randomized, controlled trials. Ann Intern Med. 136, 493-503.

[29] Kaplan, N.M., R.B. Deveraux and H.S. Miller, Jr. (1994) 26th Bethesda conference: recommendations for determining eligibility for competition in athletes with cardiovascular abnormalities. Task Force 4: systemic hypertension. J Am Coll Cardiol. 24, 885-888.

[30] Ehrlich, J.R., S.H. Hohnloser and S. Nattel (2006) Role of angiotensin system and effects of its inhibition in atrial fibrillation: clinical and experimental evidence. Eur Heart J. 27, 512-518.

[31] Brilla, C.G., R.C. Funck and H. Rupp (2000) Lisinopril-mediated regression of myocardial fibrosis in patients with hypertensive heart disease. Circulation. 102, 1388-1393. 